\title{
The Effect of Farm Input Subsidy Program on Food Poverty Dynamics in Malawi
}

\author{
Griffin Mulula, Hannah M Dunga, Steven Henry Dunga \\ North West University Vaal Triangle Campus, South Africa \\ gmulula@gmail.com,hmdunga@yahoo.co.uk, Steve.dunga@nwu.ac.za
}

\begin{abstract}
As part of poverty alleviation and reduction of food insecurity in Malawi, the Malawi Government launched the Farm Input Subsidy Programme (FISP) in 2005/06. The programme is a continuation and expansion of previous subsidy programmes which were designed for the same purpose as the current subsidy programme. Although evaluation studies show that FISP registered success in its first five years, there has been limited research analysing the effectiveness of the programme. This study purposed to investigate how the programme has contributed to food poverty transition during the period 2010 and 2013. The study adopts a Multinomial Logit Model and uses Integrated Household Panel Survey Data of 2010 and 2013 from national statistical office to measure food poverty dynamics between the two periods. Other variables which are expected to influence food poverty dynamics are also explored. Results show that FISP does not increase chances of moving out of food poverty. Rather, education greatly provides higher chances of moving out of food poverty. Between gender that have the same qualification, men have a greater probability of moving a household out of poverty. It was also found that household size has a negatively relationship with the probability of moving out of food poverty. The study recommends that government should strengthen the monitoring, evaluation and audit systems in order to make the FISP programme effective again.
\end{abstract}

Keywords: Food security, Poverty, FISP, Education, Households Size

\section{Introduction}

Food is one of the most basic needs for human survival and access to it is a basic human right. It is the role of government to ensure that all its citizens are food secure because food insecurity poses major threats to health, labour productivity as well as the survival of individuals in a country (Smith \& Subandoro, 2007). In Malawi, the battle against food insecurity has become a common policy issue for every regime because of the nature of the persistence of the problem. A series of policy documents for Malawi, spanning from the Vision 2020 to the currently Malawi Growth Development Strategy II (MGDS) have been citing food insecurity as a major problem the country is facing. The persistence of the problem is hindering the country from creating wealth through sustainable economic growth and infrastructure development, which is the main goal of the MGDS. According to the MGDS, problems of food insecurity are traced to the low and stagnant yields in the agriculture sector, which contributes significantly to national and household food security (Government of Malawi, 2006). Although Malawi has not experienced widespread famine in recent years, results from IHS3 indicate that a substantial proportion of the population experiences extreme forms of food security. About 33 percent of the population had very low food security in the year 2010 (National Statistical Office, 2012). This implies that aside from the climatic factors, there are several challenges which smallholder farmers face which leads to the low stagnant yields. In a bid to improve the agriculture sector and in turn alleviate food poverty, the Malawi government embarked on a comprehensive targeted fertilizer and seed subsidy program called the Farm Input Subsidy Program (FISP) to boost its agricultural production and to enhance household and national food security. The program was launched in the 2005/06 agriculture season. The main aim was to distribute coupons to poor households to purchase fertilizers and seeds at a subsidised price (Dorward \& Chirwa, 2011).

However, since its implementation in 2005, there are still serious reports of food shortages in the country. In the 2016 food security assessment conducted by the Ministry of Finance, Economic Planning and Development through the Malawi Vulnerability Assessment Committee (MVAC) results showed that 39 percent of Malawi's Population will not be able to meet their annual food requirements during the 2016/17 consumption period (Ministry of Finance Economic Planning and Development, 2016). It is under the mentioned shortfalls that this study aims to fill this gap by finding out whether if the FISP program has significantly eradicated poverty. The study formulated the following objectives

- Assess the economic characteristics on food poverty dynamics in Malawian households 
- Assess the effect of demographic characteristics on food poverty dynamics in Malawian households

- Assess the effect of the size of arable land available to households on food poverty dynamics.

To achieve the set objectives, the study will use the 2010 and 2013 panel data from the IHS, which will provide more information variability because it is a nation-wide survey and incorporates more variables.

\section{Literature Review}

Food poverty can be regarded as the lack of food. However, there is no sole definition and measurement of food poverty. Measurements and definitions vary from study to study and across regions. The term food poverty itself stems from the term poverty, which has the same characteristics as the former in terms of the wide variations of measurements and definitions. The concept of poverty is a dynamic and multi-dimensional phenomenon. On a global perspective, The World Bank Institute (2005) defines poverty as deprivation in well-being and well-being is viewed in three main approaches. The first approach relates to one's well-being or as the command over commodities in general, meaning that people are better off if they have a greater command over resources. In this view, the main focus is on whether households or individuals have enough resources to meet their needs. Typically, poverty is then measured by comparing an individual's income or consumption with some defined threshold below which they are considered to be poor. This is the most conventional view of poverty widely adopted by most studies (World Bank Institute, 2005). The second approach views well-being in terms of whether people are able to obtain specific types of consumption goods. For example, if an individual does not have shelter or medical care or clothes and other goods; they are regarded as poor. Therefore on this basis, poverty is defined as lack of necessities (Bradshaw, 2006). The measurement of this approach goes beyond monetary indicators and it dwells on specific goods. However, Sen (2001) argued that what is deemed as a must have is subjective across different societies, in a way that a necessity to one person may not be uniformly a necessity to others. In other words needs may be relative to what is possible and are based on social definition and past experience. The third approach was developed by Amartya Sen (1987), who views well-being as the lack of capability to function in a society. Thus poverty arises when individuals and households do not have the capability to acquire their needs. It also includes nonmaterial goods such as self-esteem, sense of power and rights. In order to distinguish the poor households from non-poor households, a poverty line is employed as a threshold in this case poverty is usually measured in terms of a monetary cost of basic needs per given person. The poverty line comprises two parts; the food and the non-food component. The food poverty line hence represents the cost of a food bundle that provides the necessary energy requirements per person per day.

In Malawi, according to the Integrated Household Survey (2012), the national poverty rate was 50.7 percent showing that almost half of the population was poor. The problem of poverty in the country hasn't improved much; World Bank (2016) indicated that poverty trends in the country are increasing especially in the rural areas where over80 percent of the population resides. Ibid further indicated that low agricultural activities the main obstacle to reducing poverty in the country. Malawi heavily depends on agriculture which contributes to nearly 31 percent of the country's GDP. However, almost 75 percent of the farming is done by smallholder farmers who cannot maximise their production due to adverse shortfalls such as limited land, limited access to credit and extension services, as such increasing food shortages in the country. The government has over the years embarked on different policies to reduce poverty in Malawi, dating from the 1970s and 80s, there were general price subsidies and subsidised credit which made the country achieve a high degree of self-reliance in Malawi's staple food, (maize). This was followed by the 1998, Starter Pack Schemes (SPS), which later evolved into Target Input Program (TIP). However, due to unfavourable weather conditions in the 2004/05 season coupled with the scaling down of TIP, The country experienced food shortages and very high maize prices in that harvest season (Chibwana et al., 2010). In 2005/06 the Government embarked on a Farm Input Subsidy Program (FISP) targeting households that could not afford to purchase farming inputs. Such households were given coupons to purchase fertilizer and seeds at a highly subsidised price (Dorward \& Chirwa, 2011). FISP is not only a Malawi phenomenon. A number of countries in Africa have also adopted the program to carter for their poor smallholder farmers. Example include: Ghana, Nigeria, Zambia, Tanzania, Rwanda, Mali and Senegal. According to Chirwa and Dorward (2013), in all the mentioned countries, the efficiency in the provision of subsidised inputs to smallholder farmers is debatable hence a number of donors do not prefer the system. Ibid further relates to Malawi case where several 
shortfalls have been discovered, the most prominent being discrepancies in the monitoring, evaluation and audit systems which are crucial for improving efficiency and effectiveness of the programmes. This study attempts to make a contribution in evaluation of the programme by assessing how the programme helped households move out of food poverty in Malawi between 2010/11 and 2013. Another problem associated with the programmes is the difficultly to graduate and achieve independence by the smallholder farmers. There seems to be no end to the programmes and beneficiaries have settled for receiving hand-outs rather than looking for alternative sources of inputs by themselves.

Since the implementation of the FISP programme, there has been a number of studies addressing the issue and have brought in mixed results. Research conducted in the early days (soon after initiation) showed that there was good progress. For example, Mussa and Pauw (2010) reported that in the FISP implementation period, there was a sharp decline in poverty from 52 to 39 percent and in ultra-poverty from 22 to 15 percent. In addition, the Government of Malawi, (2013) in the Malawi Growth and Development Strategy II also cited that the number of Malawians at the risk of hunger had decreased over time due to FISP and from 2004 to 2010, the increase in food production also contributed substantially to reduction of poverty and eradication of hunger in the country. However, despite the success story of the FISP program in its early years, recent study show that the FISP program is becoming ineffective. Holden and Lunduka, (2012) argued that while the program enhances food production and food security, it does not target the poor. They claimed that basic problems such as illegal markets for coupons and fertilizers, leakage of coupons, failure to establish a system of beneficiary and targeting are a serious problem which makes the program ineffective. In line to this, Pauw et al. (2016) used constructed regional poverty lines for Malawi and found that the program did not benefit those close enough to the poverty line to be lifted out of poverty. In addition, Mvula et al. (2011) in their qualitative evaluation of the 2010/11 farm input subsidy program also found that there were several growing challenges which hinder the FISP from reaching out to most vulnerable poor targeted beneficiaries. They found that fertilizer politics, gender discrimination of female headed households and discrimination of the elderly were some of the major problems in the program.

The above cited evidence reveals that the FISP program is slowly becoming less effective in its agenda of alleviating food poverty despite significantly moving households out of food poverty soon after its implementation. Although there have been various studies done on the FISP program and food poverty (Chirwa 2010, 2011, 2013, Shiverly \& Gilbert, 2013), there is no recent study that has been conducted with recent IHS panel data to prove the effectiveness of the FISP program in poverty alleviation. It is against this background that this research is motivated to establish if indeed the FISP program has effectively assisted in alleviating food poverty. The study will also explore demographic, economic and social characteristics that are also suspected to contribute to the movement in or out of food poverty. Instead of using food security, the study uses food poverty dynamics to measure the impact of FISP and other variables.

\section{Methodology}

In order to assess the effectiveness of the FISP on food poverty dynamics in Malawian households, the study employed a qualitative analysis to measure the in and out movement of household poverty from 2010/11 to 2013 depending on the FISP program and other factors. The study thus uses a linear probability model where the dependent variable is a dummy variable and four categories namely movement into poverty, movement out of poverty, remaining in food poverty and remaining in a non-food poverty status as the dependent variable. The outcome "remaining in food poverty" is the base category outcome. Since a multinomial logit model is an extension of the logit model where the expected outcomes are more than two, hence, a multinomial logit model becomes suitable for this research. In general, a multinomial logit model simulates a case where there are discrete categorical outcomes $\mathrm{m}, 3,2,1$ recorded in y and the explanatory variables X. Although coded, the categories for a multinomial logit model for this study are not ordered. Specifically, to explore the movement across the poverty line between 2010/11 and 2013, two multinomial logit regressions are going to be estimated. The first regression will be of initial conditions of the first round of the survey conducted in 2010/11. The second regression will compose of the initial conditions plus the changes which took place between 2010/11 and 2013. Each of these regressions will have a categorical dependent variable of four mutually exclusive categories. 
The first category describes no change in food poverty status where a household remained poor after participating in FISP from 2010/11 to 2013, the second describes movement from a food poor status in 2010/11 to a non-food poor status in 2013 while the third addresses movement from a non-food poor status in 2010/11 to a food poor status in 2013. The fourth category describes no mobility from a non-food poor status in both rounds. These categories will be labelled 1, 2, 3 and 4 respectively. The model can be expressed as follows as used by Khalid, et al., (2005). Where; $\mathrm{Y}_{\mathrm{ij}}=1$ if the $\mathrm{i}^{\text {th }}$ individual chooses the $\mathrm{j}^{\text {th }}$ alternative and $y_{i j}=0$ otherwise, where $j=1,2,3,4$

Prob $\left[\mathrm{y}_{\mathrm{ij}}=1\right]=\mathrm{P}_{\mathrm{ij}}$ and since the probabilities must add up to unity, we have $P_{i 1}+P_{i 2}+P_{i 3}+P_{i 4}=1$

Thus the multinomial logit model can be expressed as:

$$
\operatorname{Prob}(Y=\mathrm{j})=\frac{e^{\left(\alpha_{j}+\beta_{j} X_{j}\right)}}{1+\sum_{j}^{k} e^{\left(\alpha_{j}+\beta_{j} X_{j}\right)}}
$$

Where $\mathrm{k}$ is the number of outcomes being modelled. The above will express the probability that a household with characteristics $\mathrm{X}_{i}$ will lie in the $j^{\text {th }}$ category of poverty.

Description and Measurement of Variables: The advantage of the IHS panel data is that it gives a wide range of variables some of which are going to be relevant for this study. This allows the study to observe poverty dynamics while avoiding specification bias. It has to be noted that all the expected signs of the variables are described under the cateris paribus assumption. The following are the variables used in the study;

Table 1: Variable description

\begin{tabular}{lll}
\hline \multicolumn{1}{c}{ VARIABLE } & \multicolumn{1}{c}{ TYPE } & \multicolumn{1}{c}{ DESCRIPTION } \\
\hline FISPpart & Binary & If a household participated in FISP \\
cropdiversity & Continuous & Number of crops grown by a household \\
Land & Continuous & Size of arable land for a household in acres \\
business & Binary & If a household own a non-farming business \\
prim_ind & Continuous & Number of household members in primary industry \\
second_ind & Continuous & Number of household members in secondary industry \\
tert_ind & Continuous & Number of household members in tertiary industry \\
None & Binary & If maximum education by any member is none \\
Plsc & Binary & If maximum education by any member is PLSC \\
Jce & Binary & If maximum education by any member is JCE \\
Msce & Binary & If maximum education by any member is MSCE \\
tertiary & Binary & If maximum education by any member is tertiary \\
hh_size & Continuous & Number of members in a household \\
hh_headsex & Binary & Sex of household head \\
hh_headage & Continuous & Age of head of household \\
hh_headage2 & Continuous & Age of head of household squared \\
Rural & Binary & Residence of a household \\
Centre & Binary & If household is based in the central region \\
South & Binary & If household is based in the southern region \\
\hline
\end{tabular}

Food Poverty Status: This is a dummy outcome variable with 4 categories. The categorical outcomes are described as follows; 


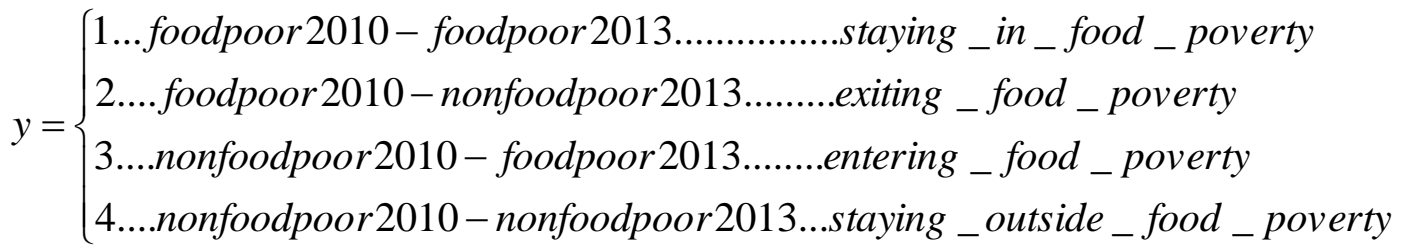

Where categorical outcome 1 is the base outcome and a food poor status is poverty status in which a household's consumption is below MK 22, 956.00

Independent variable: The independent variable is described as follows,

Empirical Model Specification: Two regression equations are going to be estimated. The first regression will estimate the changes in food poverty status in relation to the initial conditions of the households in 2010. The first regression is presented as follows.

foodpoverty_cat $=\beta_{0}+\beta_{1}$ FISPpart_2010 $+\beta_{2}$ hh_headsex_2010 ${ }_{i t}+\beta_{3}$ hh_size_2010 $+\beta_{4}$ land_2010 ${ }_{i t}+\beta_{5}$ cropdiversity_2010 $i t+\beta_{6}$ hh_headage_2010 $i t+\beta_{7}$ hh_headage $2_{-} 2010_{i t}$

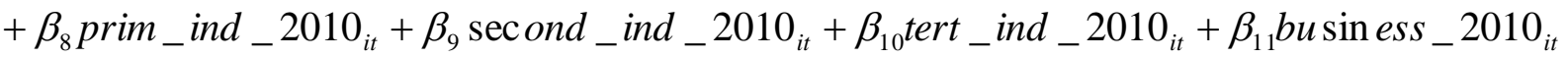
$+\beta_{12}$ none_2010 $+\beta_{13}$ plsc_2010 ${ }_{i t}+\beta_{14} j c e \_2010_{i t}+\beta_{15}$ msce_2010 $0_{i t}+\beta_{16}$ tertiary_2010 ${ }_{i t}$ $+\beta_{17}$ south $_{i t}+\beta_{18}$ centre $_{i t}+\beta_{19}$ rural $_{i t}+\mu_{i t}$

The second equation will regress the changes in food poverty status on the variables plus the changes in the variables over the period $2010 / 11$ to 2013 and is expressed as follows

foodpoverty_cat $=\beta_{0}+\beta_{1}$ FISPpart_2010 ${ }_{i t}+\beta_{2}$ hh_headsex_2010 $i t+\beta_{3}$ hh_size_2010 ${ }_{i t}$

$+\beta_{4}$ land_2010 ${ }_{i t}+\beta_{5}$ cropdiversity_2010 ${ }_{i t}+\beta_{6}$ hh_headage_2010 ${ }_{i t}+\beta_{7}$ hh_headage $2 \_2010_{i t}$

$+\beta_{8}$ prim_ind $2_{2010_{i t}}+\beta_{9}$ second $\_$ind $\_2010_{i t}+\beta_{10}$ tert_ind $\_2010_{i t}+\beta_{11}$ bu siness_2010

$+\beta_{12}$ none_2010 ${ }_{i t}+\beta_{13}$ plsc_2010 ${ }_{i t}+\beta_{14} j c e_{-} 2010_{i t}+\beta_{15}$ msce $2010_{i t}+\beta_{16}$ tertiary_2010

$+\beta_{17}$ south $_{i t}+\beta_{18}$ centre $_{i t}+\beta_{19}$ rural $_{i t}+\beta_{20}$ dFISPpart $_{i t}+\beta_{21} c_{-}$cropdiverty $_{i t}+\beta_{22} c_{-}$land $_{i t}$

$+\beta_{23} d b u \sin e s s_{i t}+\beta_{24} c_{-}$prim_ind ${ }_{i t}+\beta_{25} c_{-} \sec$ ond $\_$ind ${ }_{i t}+\beta_{26} c_{-}$tert_ind ${ }_{i t}+\beta_{27} c_{-}$hhsize

$+\beta_{28}$ dhh_headsex ${ }_{i t}+\beta_{29} c_{-}$hh_headage ${ }_{i t}+\beta_{30} c_{-}$hh_headage $2+\beta_{31}$ dnone $_{i t}+\beta_{32}$ dplsc $c_{i t}$

$+\beta_{33}$ jce $_{i t}+\beta_{34}$ dmsce $_{i t}+\beta_{35}$ dtertiary $_{i t}+\mu_{i t}$

Where $i$ is the $i^{t h}$ household in the study and $t$ is the initial period under observation, 2010/11.

\section{Results and interpretation}

The results are interpreted as follows,

Food poverty transition matrices: The food poverty transition matrices are statistics that describe the movement across the food poverty line. In this study, the transition matrices are represented by the dependent variable food poverty.

Table 2: Frequency, Percentage and Cumulative distribution of food poverty status

\begin{tabular}{llll}
\hline Food Poverty Status & Frequency & Percentage & Cumulative \\
\hline Remained food poor & 20 & 1.04 & 1.04 \\
Exited food poverty & 134 & 6.98 & 8.02 \\
Entered food poverty & 97 & 5.05 & 13.07 \\
Remained non-food poor & 1670 & 86.93 & 100.00 \\
Total & 1921 & 100 & \\
\cline { 1 - 2 }
\end{tabular}


From table 2, it can be seen that after cleaning the data, a sample of 1,921 households remained for study. 20 households remained poor in the period between 2010/11 and 2013, representing 1.04 percent while 134 household exited food poverty representing 6.98 percent. Meanwhile, 97 (5.05 percent) households entered into food poverty while the remaining 1670 (86 percent) did not change their food status.

Diagnostic Tests Results: Three diagnostic tests were run in the study, pair wise correlation, Hausman test and a Wald test. In all tests $\alpha=0.05$, the results for pair wise correlation showed a correlation of 0.9306 between the variable hh_headage_2010 and hh_headage2_2010. As Gujarati (2004) suggests, a pair wise correlation greater than 0.8 depicts serious levels of multicollinearity. As a result, the variable hh_headage2_2010 was not included in the regression. For the Huasman test, it was found that the chi-square for all the categories of the dependent variables did not exceed the chi-critical therefore, it was concluded that there was no sufficient evidence to reject the null hypothesis since the test statistics are not significant. Thus the IIA assumption of the MNL model was not violated. Finally, a Wald test showed that at a chi-square value of 1114.75 with 48 degrees of freedom, there is a p-value of 0.0000 . Therefore we reject the null hypothesis that the coefficients of change variables were not jointly significant. Thus, the study will proceed to run two regressions; one of initial conditions and the other of initial conditions plus the change variables.

Multinomial Logit Regression Results: In this final section, results of the two regressions are going to be presented starting with the initial conditions regression then following the initial conditions plus change variables regression. Due to the nature of the multinomial logit model, marginal effects are used to interpret the data. The remained poor category is used as the referral category. As such all interpretations will be based on that category.

Regression of Initial Conditions in 2010: In this regression, the results show that the model has a pseudo R-squared of 19 percent. This means the regression model explains 19 percent of the variability in the outcomes of food poverty. The results are shown in table 3.

Table 3: Marginal effects for initial conditions regression

\begin{tabular}{|c|c|c|c|c|c|c|}
\hline Variable & Exit & Standard error & Entry & $\begin{array}{c}\text { Standard } \\
\text { error }\end{array}$ & $\begin{array}{l}\text { Remain non- } \\
\text { food poor }\end{array}$ & $\begin{array}{c}\text { Standard } \\
\text { error }\end{array}$ \\
\hline FISPpart_2010 & -0.01633 & $(0.011056)$ & 0.009157 & $(0.015028)$ & 0.015221 & $(0.018538)$ \\
\hline cropdiversity_2010 & $-0.01962^{* * *}$ & $(0.005522)$ & $-0.0317^{* * *}$ & $(0.009682)$ & $0.05398^{* * *}$ & $(0.010699)$ \\
\hline land_2010 & -0.00195 & $(0.005394)$ & $-0.03506^{*}$ & $(0.014101)$ & $0.036135^{* *}$ & $(0.014016)$ \\
\hline business_2010 & $-0.04003^{* *}$ & $(0.01654)$ & -0.02541 & $(0.019763)$ & $0.073279^{* * *}$ & $(0.025121)$ \\
\hline prim_ind_2010 & -0.00022 & $(7.049114)$ & 0.047033 & $(1.726278)$ & 0.103359 & $(21.365)$ \\
\hline second_ind_2010 & -0.8208 & $(120.2879)$ & -0.70705 & (147.5289) & 1.632169 & $(174.5733)$ \\
\hline tert_ind_2010 & -0.76023 & $(147.4413)$ & -0.65813 & $(167.4746)$ & 1.513825 & $(204.8451)$ \\
\hline none_2010 & $0.026778^{* *}$ & $(0.013238)$ & -0.01547 & $(0.019036)$ & -0.00635 & $(0.023038)$ \\
\hline plsc_2010 & 0.048815 & $(9.550346)$ & -0.75638 & $(106.6676)$ & 0.845447 & (99.4581) \\
\hline jce_2010 & 0.039662 & (11.68184) & -0.76633 & $(145.3347)$ & 0.857861 & (134.3993) \\
\hline msce_2010 & -0.79123 & (181.4326) & -0.70818 & $(218.7491)$ & 1.604022 & $(262.3748)$ \\
\hline tertiary_2010 & -0.62747 & (211.879) & -0.6873 & $(244.9812)$ & 1.386841 & $(296.605)$ \\
\hline mscefem_2010 & 0.093552 & $(465.2066)$ & -0.02139 & $(529.0167)$ & -0.08326 & $(650.7519)$ \\
\hline mscemal_2010 & 0.921432 & (511.767) & 0.662006 & $(557.8207)$ & -1.70414 & (699.5586) \\
\hline hhsize_2010 & $0.021068^{* * *}$ & $(0.002431)$ & $0.011835^{* * *}$ & $(0.003152)$ & $-0.0365^{* * *}$ & $(0.003963)$ \\
\hline hh_headsex_2010 & $-0.02237^{*}$ & $(0.012909)$ & -0.0179 & $(0.016078)$ & $0.046965^{* *}$ & $(0.02059)$ \\
\hline hh_headage_2010 & 114.17 & $(0.000381)$ & -74.89 & $(0.000421)$ & 0.000137 & $(0.000564)$ \\
\hline rural_2010 & $-4.59^{* * *}$ & $(0.035366)$ & -0.01262 & $(0.016614)$ & $-0.1803^{* *}$ & $(0.037266)$ \\
\hline centre_2010 & $-0.02767^{*}$ & $(0.015376)$ & -105.88 & $(0.017325)$ & $-21.2^{*}$ & $(0.022855)$ \\
\hline south_2010 & $0.033602^{* *}$ & $(0.013458)$ & 0.010106 & $(0.016849)$ & $-0.03659 *$ & $(0.021414)$ \\
\hline
\end{tabular}

\footnotetext{
$*^{* *}$ and ${ }^{* * *}$ represent significance at $10 \%, 5 \%$ and $1 \%$ respectively. Standard errors in parentheses
} 
FISP participation: Holding all other independent variables constant and with reference to the "remained food poor" category, participating in FISP negatively affects exit from food poverty. Participating in FISP reduces the chances of getting out of food poverty by 1.6 percentage points. This does not conform to our apriori expectations. However, the variable is not significant in all the three outcomes. This is possibly because participating in the programme does not have a huge impact on those households which are food poor as Mvula et al. (2011) found. Participating in FISP increases the chances of moving into food poverty by 1.5 percent and influences entry into food poverty by 0.9 percentage points.

Crop diversity: Just like participation in FISP, assuming all other independent variables are held constant and with reference to the remained food poor category, an addition of the number of crops grown reduces chances of food poverty exit by 1.9 percentage points. This outcome is contrary to the expectation of the study. An addition of number of crops grown reduces chances of entry into poverty by only 3 percentage points and increases the chances of remaining non-food poor by 5 percent. The latter two outcomes conform to apriori expectations. The variable is statistically significant in all outcomes at 1 percent.

Land: Similarly, one acre addition to land does not reduce chances of exit from poverty holding all other variables constant and with reference to the remained food poor category. One acre addition of land reduces the chances of exiting from food poverty by 0.2 percent, which is insignificant and does not conform to expectations. This is possibly because households who are food poor cannot afford to get the best out of the additional land due to their poverty status. A unit addition of land increases the chances of remaining nonfood poor and reduces the chances of slipping into food poverty by 4 percentage points each. The variable is significant at 10 percent for "entry" outcome and at 5 percent for the "remain non-food poor" outcome.

Business: Holding all other independent variables constant and with reference to the remained food poor category, owning a business reduces the chances of exiting from poverty by 4 percentage points than not owning a non-farm business. It reduces the chances of entry into food poverty by 3 percentage points and increases the chances of remaining non-food poor by 4 percentage points. Only the exit from food poverty outcome does not conform to apriori expectations. The variable is significant for "exit" outcome at 5 percent and for "remain non-food poor" at 1 percent.

Employment Variables: Holding all other independent variables constant and with reference to the remained food poor category, an addition member of a household employed in the primary sector barely affects the chances of exiting food poverty by -0.02 percentage points. It increases the chances of entering into food poverty and remaining non-food poor by 5 and 10 percentage points respectively. For the secondary employment sector variable, an addition of one household member employed in the secondary sector negatively affects chances of exiting poverty by 82 percentage points. This is surprisingly not expected in this research. However, it significantly reduces chances of entering into food poverty by 71 percentage points and increases the chances of remaining in non-food poor by 163 percentage points. For tertiary employment sector variable, an addition of one household member employed in the tertiary sector reduces chances of exiting food poverty by 76 percentage points and reduces chances of entry into poverty by 65 percentage points. An addition of a member employed in the tertiary sector increases chances of remaining non-food poor by 151 percentage points. All the employment variables are statistically insignificant.

Education Variables: Assuming all other influences on food poverty outcome are kept constant and still using the remain food poor as our referral category, the following is how education variables influence food poverty outcomes;

- If a household has adult members with no maximum level of education, chances of exit, entry and remaining in food poverty are $3,-1.5$ and -0.6 percentage points respectively. Increasing chances of exit from food poverty by 3 percentage points and reducing chances of entry by 1.5 percentage points does not conform to expectations. However, the results are not practically significant.

- If a household has adult members with primary school leaving certificate as maximum level of education, chances of exit, entry and remaining in food poverty are 5, -7.5 and 85 percentage points respectively. These results conform to the expectation of the study.

- If a household has adult members with Junior Certificate as maximum level of education, chances of exit, entry and remaining in food poverty are $4,-77$ and 86 percentage points. If a household has 
adult members with Malawi School Leaving Certificate as maximum level of education, chances of exit, entry and remaining in food poverty are $-80,-71$ and 160 percentage points. Surprisingly, there is a negative relationship between the outcome exit from food poverty and having a maximum number of adults with an MSCE, which is contrary to expectations of this study. If a household has adult members with tertiary qualification as maximum level of education, chances of exit, entry and remaining in food poverty are $-63,-69$ and 139 percentage points. Again, the negative relationship between exit from food poverty and having a maximum number of individuals with a tertiary qualification does not match with expectations of the study.

From the results, it can also be seen that the sex of the individual who has the education qualification significantly matters. All things being equal, an addition of a female member with an MSCE increases the chances of exiting food poverty by 9 percent while an addition of a male member with an MSCE increases the chances of escaping food poverty by 92 percentage points. However, an addition of a male member with an MSCE increases chances of entry into poverty by 66 percentage and reduces chances of remaining non-food poor by 177 percentage points. This does not match the study's expectations.

Household Characteristics: Cateris paribus, an addition member to a household increases the chances of exiting food poverty by 2 percentage points. This is not in line with the expectation of the study. The addition also increases chances of entry into food poverty by 1 percentage point. It also reduces the chances of remaining non-food poor by 4 percentage points. This variable is significant at 1 percent. All things being equal, if the household head is a male, chances of exiting food poverty lower by 2 percentage points and chances of entering poverty are reduced by 2 percentage points while chances of remaining non-food poor are also higher by 5 percent. This is contrary to our expectation. Cateris paribus, it is found that an additional increase in household head age increases the chances of exiting food poverty, reduces the chances of entering into food poverty and also increases the chances of remaining in a non-food poor state.

Location and region: Holding all other variables constant, a household in the rural part of Malawi has less chances of escaping food poverty compared to the rural household by 459 percentage points. This conforms to the expectation of the study. Chances of entry into poverty are higher by 1 percentage point for households in the rural and chances of staying outside food poverty are also less by 18 percentage points. For this rural variable, only the outcome for entry into poverty is statistically insignificant. This is possibly because the sample consists of a majority of households who reside in rural areas and are already in food poverty. Cateris paribus, residing in the central region reduces chances of exiting poverty by 3 percentage points compared to residing in the northern region. This is significant under 5 percent. It also reduces chances of entering into food poverty by 106 percentage points. This is insignificant statistically. Residing in the central region also reduces chances of maintaining a non-food poverty status by 21 percentage points and this is significant under 10 percent. Residing in the southern region of Malawi increases chances of exiting from food poverty by 3 percentage points more than living in the north and it increases chances of staying non-food poor by 4 percentage points more than the rural residents.

Regression of Initial Conditions plus Change Variables: The regression of initial conditions plus changes is worth observing because it has more explanatory power of the variability in the food poverty outcome. The pseudo R-squared of this regression is higher than that of the initial conditions at 27 percent.

FISP participation and crop diversity: There are differences in the significance of the variables. Notably, in the FISP participation variable, the outcome of chances of exit from food poverty which was insignificant in the first regression is now significant in the second regression at 10 percent. This means that all things being equal, chances of escaping poverty reduce by 3 percentage points if a household participates in the program. Again, crop diversity is no longer significant in influencing the exit from food poverty but it is still significant in the other two outcomes; entry into food poverty and remaining in non-food poverty status.

Land and Business: Land has no longer a significant influence on the chances of remaining non-food poor but it still has a significance on reducing chances of entry into food poverty now at 1 percent level of significance. Business is no longer a significant variable in the second regression. This is possibly due to the 
small-scale nature of the non-farming businesses which most Malawians are engaged in. These kinds of business fail to make a significant impact on the food poverty status of households.

Employment Variables: To the surprise of this study, all the employment variable has no significant influence on the poverty outcomes. This is possibly because the sample consists of a larger proportion of households who have individuals who are not involved in any kind of work and those who work have very low earnings which fail to make an impact on the food poverty status of the households.

Table 4: Marginal effects of Initial Conditions plus Change Variables regression

\begin{tabular}{|c|c|c|c|c|c|c|}
\hline Variable & Exit & Standard error & Entry & $\begin{array}{l}\text { Standard } \\
\text { error }\end{array}$ & $\begin{array}{r}\text { Remain } \\
\text { non-food } \\
\text { poor }\end{array}$ & $\begin{array}{r}\text { Standard } \\
\text { error }\end{array}$ \\
\hline FISPpart_2010 & $-0.02588 *$ & $(0.014552)$ & 0.014872 & $(0.015222)$ & 0.015199 & $(0.020961)$ \\
\hline cropdiversity_2010 & -0.01282 & $(0.007952)$ & $-0.03344^{* * *}$ & $(0.009338)$ & $0.053^{* * *}$ & $(0.012174)$ \\
\hline land_2010 & 0.003485 & $(0.013138)$ & $-0.04064^{* * *}$ & $(0.014809)$ & 0.030582 & $(0.019529)$ \\
\hline business_2010 & -0.00185 & $(0.041712)$ & -0.01689 & $(0.024996)$ & 0.033678 & $(0.04833)$ \\
\hline prim_ind_2010 & -0.01487 & (5.834547) & 0.050119 & $(4.248574)$ & 0.097822 & (22.36283) \\
\hline second_ind_2010 & -0.86319 & (145.0206) & -0.58982 & (136.5908) & 1.536671 & (184.8577) \\
\hline tert_ind_2010 & -0.78405 & (171.5621) & -0.54935 & (144.6415) & 1.398487 & (208.7695) \\
\hline none_2010 & $0.024579 *$ & $(0.013135)$ & -0.02059 & (0.017999) & -0.00244 & $(0.021995)$ \\
\hline plsc_2010 & 0.024348 & (8.028383) & -0.65774 & $(96.02257)$ & 0.74494 & $(90.08264)$ \\
\hline jce_2010 & 0.015013 & $(9.962696)$ & -0.681 & (126.3901) & 0.777093 & (117.8219) \\
\hline msce_2010 & -0.82866 & (224.8969) & -0.6382 & $(222.8074)$ & 1.554399 & (294.5094) \\
\hline tertiary_2010 & -0.66445 & (243.0678) & -0.56839 & (222.4777) & 1.281764 & (305.1923) \\
\hline mscefem_2010 & 0.106126 & (547.5545) & -0.01379 & (499.7509) & -0.09629 & (693.0803) \\
\hline mscemal_2010 & 0.861112 & (599.7131) & 0.524803 & (552.2658) & -1.99099 & (763.4786) \\
\hline hhsize_2010 & $0.017001^{* * *}$ & $(0.003325)$ & $0.01741^{* * *}$ & $(0.002923)$ & $-0.04^{* * *}$ & $(0.004694)$ \\
\hline hh_headsex_2010 & -0.01464 & $(0.016434)$ & 0.010878 & $(0.017039)$ & 0.00724 & $(0.023926)$ \\
\hline hh_headage_2010 & -0.00018 & $(0.000512)$ & $0.00096^{* *}$ & $(0.000446)$ & -0.00053 & $(0.000679)$ \\
\hline rural_2010 & $0.161061^{* * *}$ & $(0.035138)$ & -0.00655 & $(0.018373)$ & $-0.18^{* * *}$ & $(0.038597)$ \\
\hline centre_2010 & $-0.03242^{* *}$ & $(0.015448)$ & $0.03487^{*}$ & $(0.018702)$ & 0.006502 & $(0.023897)$ \\
\hline south_2010 & $0.025864^{*}$ & $(0.013678)$ & $0.048012^{* *}$ & $(0.018915)$ & $-0.07^{* * *}$ & $(0.022928)$ \\
\hline dFISPpart & -0.008 & (0.014409) & -0.01317 & (0.009957) & 0.014368 & $(0.01748)$ \\
\hline c_cropdiversity & 0.007949 & $(0.006556)$ & $-0.00918 *$ & $(0.004678)$ & 0.005817 & $(0.008123)$ \\
\hline c_land & 0.00532 & $(0.012128)$ & -0.00702 & $(0.00719)$ & -0.0013 & $(0.013888)$ \\
\hline Dbusiness & 0.0408 & $(0.041601)$ & 0.004234 & $(0.020024)$ & -0.03922 & $(0.045371)$ \\
\hline c_hhsize & $-0.00638^{*}$ & $(0.003665)$ & $0.01532^{* * *}$ & $(0.002151)$ & $-0.01^{* * *}$ & $(0.004189)$ \\
\hline dhh_headsex & -0.07756 & $(0.60494)$ & -0.05603 & $(0.440087)$ & -0.38856 & (2.318129) \\
\hline c_hh_headage & 10.87 & $(0.000485)$ & $0.000617 *$ & $(0.000348)$ & -0.00055 & $(0.000594)$ \\
\hline
\end{tabular}

$*, * *$ and ${ }^{* * *}$ represent significance at $10 \%, 5 \%$ and $1 \%$ respectively. Standard errors in parentheses

The margins above portray similar effects on the outcome of the food category statuses. The signs of the independent variables in the initial conditions regression are the same with those in the second regression of initial conditions plus change variables.

Education Variables: Similarly, education variables still remain insignificant and the variable household size remains significant. Meanwhile, the variable household head sex loses its significance. In the second regression, age of household head is now significant at 5 percent in terms of its influence on entry into poverty. This means that cateris paribus, an addition of one year to the age of household age increases chances of entry into food poverty by 0.1 percentage point.

Location and Region variables: There is no change in significance in the rural variable between the two regressions. The variable centre is now significant at 1 percent in influencing the outcome of entering in food poverty. This implies that all things being equal, residing in the central region increases chances of slipping 
into food poverty more than residing in the north by 3 percentage points. In addition, the variable south is also significant at 5 percentage points in influencing the outcome of entering in food poverty. This implies that residing in the south increases the chance of entering food poverty by 5 percentage points more than residing in the north.

Change variables: Change in FISP participation in not significant in all the three outcomes. This is possibly because the benefits of the program do not suffice for the food needs of a household. If a household which was not participating in FISP in year 2010 joins the programme in 2013, it reduces its chances of exiting food poverty by 0.8 percentage points, reduces chances of entering into food poverty by 1 percentage point and increases chances of remaining non-food poor by 1.4 percentage points, cateris paribus. Crop diversity is only significant at 10 percent in the entry outcome. This means a household which has grown one additional new crop by 2013 reduces its chances of entering into food poverty by 1 percentage points assuming all other variables are held constant. Land and business change variables were found to be insignificant. This is possibly because increasing the land to cultivate does not bring significant returns to affect a food poverty status. Similarly, returns from non-farm business for Malawian households are very small and thus to not make a significant profit.

Cateris paribus, change in household size between 2010 and 2013 reduces chances of exit, entry and remaining in non-food poverty by $0.6,-1.5$ and 1 percentage points. This variable is significant for the exit outcome at 10 percent and for the entry and remaining in food poverty at 1 percent significant level. Change of sex of the household is also not significant in the second regression. This is possibly because between 2010 and 2013, there had not been many changes in the sex of the household. Change in age of household is significant only for the entry into food poverty outcome at 1 percent level of significance. Additional years of the household head between 2010 and 2013 increased the chances of moving into food poverty by 0.062 percentage points.

\section{Conclusion}

Transition matrices show that out of a sample of 1921 used in the study, about 7 percent exited food poverty and 5 percent entered food poverty while 1 percent remained in food poverty. This indeed alludes to the fact poverty is a dynamic concept. Two regressions were run in the study; the regression of initial conditions and the regression of initial conditions plus the change variables. It was found that the regression which incorporated the change variables had a higher explanatory power of the variability in the model at pseudo Rsquared equal to 27 percent compared to the regression of initial conditions which had an explanatory power of 19 percent. For this reason, the study is going to use the second regression to draw conclusions. Based on the objectives set by the study which were; to assess the effect of FISP on food poverty dynamics, to assess the effect of economic characteristics on food poverty dynamics, to assess the effect of demographic characteristics on food poverty dynamics and to assess the effect of size of arable land available to a household on food poverty dynamics, the following results were found; Participation in the FISP programme does not increase chances of getting out of food poverty. In fact, according to the results of this study, participating in FISP reduces chances of getting out of poverty and also it increases chances of entering into food poverty. For those who were not in food poverty, participating in the programme increases their chances of remaining in that status. Therefore, it can be said that the programme only benefits those who are not food poor.

Secondly, it was found that among economic characteristics which were used in this study, education has more pronounced effects than any other group of variables. In addition, a social issue in terms of gender was discovered. Males who have an MSCE have more influence on moving a household out of food poverty than females. This is possibly due to gender biases because it is expected that individuals who have the same education qualification have the same economic contribution, all things being equal. In the demographic variables, cateris paribus, a unit increase in household size reduces the chances of getting out of food poverty. This is also true for change in household size which takes place between 2010 and 2013. A change in household head to a female also reduces chances of getting out of food poverty. A one year increase in head of household age has no influence on exit from poverty. This is probably because a one year in age change cannot have an immediate impact on food poverty status. A change in age between 2010 and 2013 has more 
pronounced positive effects on chances of exiting poverty. Finally, an increase in land cultivated by a household increases chances of getting out of poverty assuming all this are equal.

Policy Implications: From the above conclusions, the following can be suggested for government to consider addressing the problem of food poverty. First of all, from the results of the study, it is evident that the FISP programme is no longer effective as it used to be in its first five years. Government should strengthening monitoring and evaluation programmes to help track loopholes in the programme. As Chirwa \& Doward (2013) found out, there are weak monitoring, evaluation and audit systems in the subsidy programme. This encourages corruption and brides within the programme. Alternatively, policy makers should consider abandoning the programme and explore channels through which they can affect food poverty. This is suggested so because subsidies come at a very cheap cost to the beneficiaries. This retards the beneficiaries' work ethics and they start to over depend on the subsidised inputs. This can also be a possible explanation as to why the programme is recently being ineffective as compared to the first five years. Government should consider focusing on programmes aimed at capacity building skills development. These kinds of programmes assure sustainability and encourage responsibility of citizens for their own welfare. Subsidy programmes should only be used in cases of emergency.

Policy makers should also consider providing more education opportunities to its citizens. As it has been seen in the results, owning an education qualification above JCE greatly increases the chances of escaping food poverty. As such, more focus for policy planners should be on providing secondary and tertiary education to its citizens. Instead of subsidising farm inputs, which has proven to be ineffective in the long run, government should consider subsidising secondary and tertiary education which has long term benefits. Policy planners must also ensure that there are equal opportunities between males and females. This will help government get the best out of female's potential economic productivity, which is barren by gender biases. Another suggestion government should consider is curbing population growth. This can be done through encouraging family planning programmes and sensitising households on the benefits of having a smaller family size and the consequences of large families and rapid population growth. Lastly, government must strengthen and support institutions which aim agricultural productivity. This is so because land available to household is a very limited resource and households cannot keep on increasing land to escape food poverty. As such, individuals need to be equipped with techniques and resources, other than subsidies which can improve agricultural productivity.

\section{References}

Bradshaw, T. K. (2006). Theories of Poverty and Anti-Poverty Programs in Community Development. Rural Poverty Research Center, 06(05).

Chibwana, C., Fisher, M., Jumbe, C., Masters, W. \& Shively, G. (2010). Measuring the Impacts of Malawi's Farm Input Subsidy Program. African Journal of Agriculture and Resource Economics, 3, 132-147.

Chirwa, E. W., Dorward, A. \& Matita, M. (2011).Conceptualising graduation from agricultural input subsidies in Malawi. Future Agricultures working paper 29.

Chirwa, E. \& Dorward, A. (2013). Agricultural Input Subsidies: The Recent Malawi Experience. United Kingdom: Oxford University Press.

Chirwa, E., Mvula, P. M., Dorward, A. \& Matita, K. (2010). Gender and Intra Household Use of Commercial and Subsidized Fertilizers in the Malawi Farm Input Subsidy Programme. Evaluation of the 2010/11 Farm Input Subsidy Programme. Malawi Government and DFID (Malawi).

Dorward, A. \& Chirwa, E. (2011). The Malawi agricultural input subsidy programme: 2005/06 to 2008/09. International Journal of Agricultural Sustainability, 9(1), 232-247.

Gujarati, D. N. (2004). Basic Econometrics (4th ed.). New York: McGraw-Hill.

Holden, S. \& Lunduka, R. (2012). Who Benefit from Malawi's Targeted Farm Input Subsidy Program? Forum for Development Studies, 40(1), 1-25

Khalid, U., Shahnaz, L. \& Bibi, H. (2005). Determinants of Poverty in Pakistan: A Multinomial Logit Approach. The Lahore Journal of Economics, 10(1), 65-81.

Ministry of Finance Economic Planning and Development. (2016). Results of the 2016 Food Security Assessment [Press release] 


\section{Journal of Economics and Behavioral Studies (ISSN: 2220-6140)}

Vol. 9, No. 2, pp. 131-142, April 2017

Mussa, R. \& Pauw, K. (2010). Poverty in Malawi: Current Status and Knowledge Gaps. Washington DC. International Food Policy and Research Institute.

Mvula, P. M., Chirwa, E. W., Matita, M. M. \& Dorward, A. (2011). Challenges of Access to Farm Input Subsidy by Most Vulnerable Groups in Malawi Evaluation of The 2010/11 Farm Input Subsidy Programme, Malawi.

National Statistical Office. (2012). Integrated Household Survey 2010-2011 Household Socio-Economic Characteristics Report. Zomba.

Pauw, K., Beck, U. \& Mussa, R. (2016). Did rapid smallholder-led agricultural growth fail to reduce rural poverty? Making sense of Malawi's poverty puzzle. Arndt C, McKay A, and F. Tarp (eds), Growth and Poverty in Sub-Saharan Africa, Oxford University Press: Oxford, pp.89-111.

Sen, A. (1987). The Standard of Living: Lecture I, concepts and critiques. Cambridge: Cambridge University Press.

Sen. (2001). Development as Freedom. Oxford New York: Oxford University Press.

Shively, G. E. \& Ricker-Gilbert, J. (2013). Measuring the Impacts of Agricultural Input Subsidies in Sub-Saharan Africa: Evidence from Malawi's Farm Input Subsidy Program. Purdue Policy Research Institute (PPRI) Policy Briefs, 1(1), 4.

Smith, L. C. \& Subandoro, A. (2007). Food Security in Practice: Measuring food Security Using Household Ependiture Surveys. (DOI: 10.2499/0896297675). Washington, DC.

World Bank. (2016). Malawi country overview. Retrieved on $7^{\text {th }}$ March, 2017, fromhttp://www.worldbank.org. 